\title{
Hydrogen Peroxide Mediates Suberization, Root Thickness and Stomatal Movement in Wheats
}

\author{
Santosh Kumari $^{{ }^{*}}$ and Vipin Kumar Verma ${ }^{2}$ \\ ${ }^{1}$ Division of Plant physiology, Indian Agricultural Research Institute, Delhi, India \\ ${ }^{2}$ Department of Pharmacology, All India Institute of Medical Sciences, New Delhi, India \\ *Corresponding author
}

\section{A B S T R A C T}

Keywords

Anatomy, Root Morphology,

stomatal movement, suberin, Peroxidase

Article Info

Accepted:

17 March 2019

Available Online:

10 April 2019
Plants with dense suberized root hair and low suberization of cortical cells display lower stomatal density and open stomata which signify the higher demand of water absorption. Guaiacol peroxidase play remarkable role in suberin biosynthesis on epidermis, cortex accompanied with increased root diameter, and endodermis cell walls with hydrogen peroxide spray treatment under normal conditions for plant growth i.e. November. Hydrogen peroxide decreased the in-gel activity of the peroxidase in roots of both wheats. Stomatal opening and isoenzymes of catalase were decreased under salinity and hydrogen peroxide treatment under normal and Januarv sown wheats.

\section{Introduction}

Root architecture plays important role under environmental stresses and responds to nutrient and water availability. Plants balance root and shoot growth by coordination of stomatal opening and closing for balancing photosynthesis with availability of water. Reactive oxygen species (ROS) production in the chloroplast, mitochondria and peroxisomes is increased and adversely affect plant metabolism under stress conditions. Hydrogen peroxide $\left(\mathrm{H}_{2} \mathrm{O}_{2}\right)$ has been shown to exert beneficial (low concentration) and harmful effect when in excess (Quan et al.,
2008). Foliar application of $\mathrm{H}_{2} \mathrm{O}_{2}$ has been reported to increase antioxidant enzymes and decrease lipid peroxidation under stress conditions.

Alteration in root and shoot growth of wheats has been shown in wheats under unfavourable growth condition due to abscisic acid mediated production of $\mathrm{H}_{2} \mathrm{O}_{2}$ (Santosh Kumari, 2010).

Therefore, the study was conducted to examine how does Hydrogen peroxide mediate suberization, root thickness and stomatal movement in wheats? 


\section{Materials and Methods}

C306 (drought tolerant) and HD2428 (drought susceptible) wheat cultivars were raised in earthen pots of $30 \times 30 \mathrm{~cm}$ size filled with sandy loam soil and farmyard manure in 3:1 under natural environment on $20^{\text {th }}$ November 2018 and $20^{\text {th }}$ January 2019. Hydrogen peroxide $(10 \mathrm{mM})$ was sprayed on whole shoot in the evening after one month of seedling emergence. Each pot was fertilized corresponding to 120,90 and $60 \mathrm{~kg} \mathrm{ha}^{-1}$ of $\mathrm{N}$, $\mathrm{P}$ and $\mathrm{K}$, respectively; five days after spray treatment. Six plants were maintained in each pot. Data for stomatal density and movement was recorded on fully developed flag leaf of wheats.

Root anatomical analysis and in gel enzyme staining activity of peroxidase (POX), catalase (CAT) and Superoxide dismutase (SOD) was done ten days after hydrogen peroxide treatment following (Ulmer et al., 1971; Woodbury et al., 1971, and Beauchamp and Fridovich, 1971 respectively). Fresh samples were immediately ground in liquid nitrogen and homogenized in $50 \mathrm{mM}$ phosphate buffer ( $\mathrm{pH} 7.0$ ) containing $2 \mathrm{mM}$ EDTA and 4\% PVP and centrifuged at 10,000 for $30 \mathrm{~min}$ at $4^{\circ} \mathrm{C}$. Enzyme analysis was done at various intervals to confirm the results. These plants were used for images of root morphology in wheats. Stomatal density and size were recorded on epidermal imprints following modification in Sampson's (1961) method on adaxial side of flag leaf under light microscope (Nikon Eclipse E200).

\section{Results and Discussion}

Hydrogen peroxide increased leaf area $\left(193.14 \mathrm{~cm}^{2}\right.$ per plant as compared to control $148.24 \mathrm{~cm}^{2}$ of HD2428) and adventitious roots thickness (Fig. 1A). $\mathrm{H}_{2} \mathrm{O}_{2}$ manipulated the number of root hairs and cortex cell thickness by suberin biosynthesis (Fig. 1B, 1C and 2) via inducing Guaiacol peroxidase in wheat roots under challenging as well as normal environmental conditions. Any stimulus that increases ROS/or decreases antioxidant activity will induces oxidative stress, therefore, disturb the redox environment i.e. the appropriate pools of NADPH and NADH away from the physiological range that interfere with signalling pathway. Altered protein conformation may modify its function by activation or inactivation by redox environment. The post translational thiolbased modulation of antioxidant enzyme activity suggests a role for oxidative signalling in GSH homeostasis in plants. Thiol groups are involved in ROS sensing by Ethylene receptor1 which mediates stomatal closure in response to $\mathrm{H}_{2} \mathrm{O}_{2}$. Higher redox state of guard cell ascorbate resulted in enhanced water loss and played important role in less responsive stomatal opening to $\mathrm{H}_{2} \mathrm{O}_{2}$ and $\mathrm{ABA}$ signalling under drought (Chen and Gallie, 2004). ABA induced stomatal closure has been suggested to be enhanced by reduced catalase activity (Jannat et al., 2011a). Catalase isoenzymes (Fig. 3) in roots under salinity and control condition in $\mathrm{H}_{2} \mathrm{O}_{2}$ sprayed wheats are in concurrence (Desikan et al., 2006: Tanaka et al., 2005) when ABA and Ethylene are present and ROS are removed quickly after an oxidative burst, the stomatal closure was reversed.

Under intense light stress, cell chloroplast can generate various types of ROS that influence the nuclear encoded genes and trigger apoptosis (Danon et al., 2005; Santosh Kumari, 2010). ABA accumulates in response to intense light stress and antioxidant pigments expression help in acclimation to photo oxidative stress (Santosh Kumari, 2010) in wheats. Cysteine residues of phototropins involved in their activities, in guard cells have been suggested the target of $\mathrm{H}_{2} \mathrm{O}_{2}$ (Salomon et al., 2000). An increase in ABA concentration which is mediated by 
$\mathrm{H}_{2} \mathrm{O}_{2}$ accumulation stimulates stomatal closure. Singlet oxygen has been proposed to be major ROS responsible for photo oxidative damage; key signal molecules involved in cellular responses and antagonise the effects of super oxide anion/ $\mathrm{H}_{2} \mathrm{O}_{2}$ on gene expression. Hydrogen peroxide spray treatment reduces SOD and POX (1C) isozymes in flag leaf.

Fig.1a

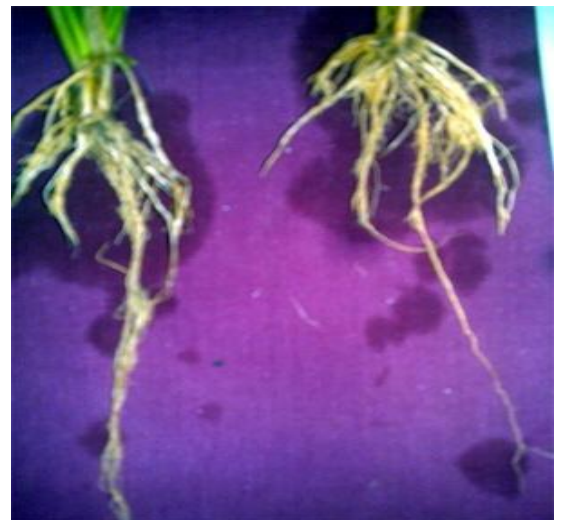

HD2428

$+\mathrm{H} 2 \mathrm{O} 2$

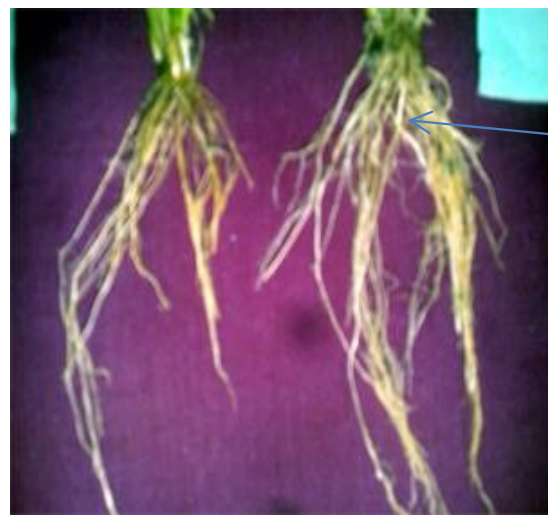

C306 +H2O2

\section{Adventitious root}

Fig1A. Hydrogen peroxide increased diameter of adventitious root

Fig.1b
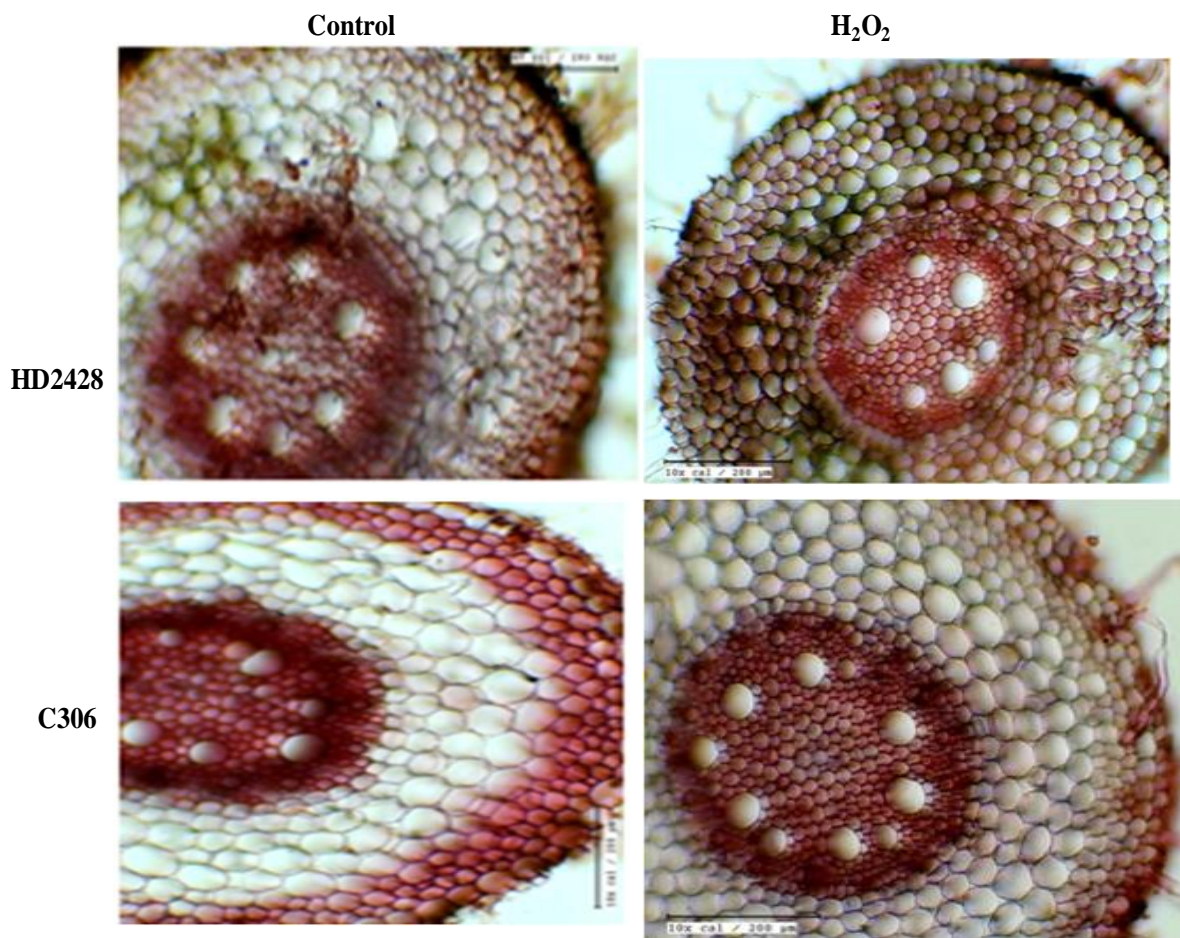

Fig1B. Suberization in cortex, root hair and diameter were altered with hydrogen peroxide spray treatment in wheats 


\section{Fig.1c}

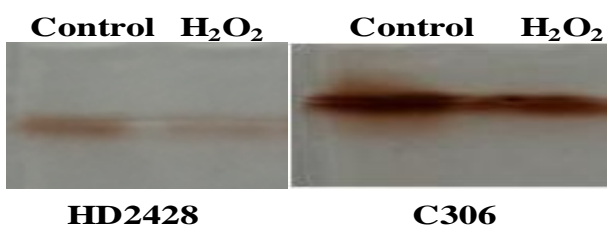

Fig1C. Root growth (root hair and root diameter) were altered via Guaiacol peroxidase by hydrogen peroxide spray treatment in flag leaves of wheats

Fig. 2

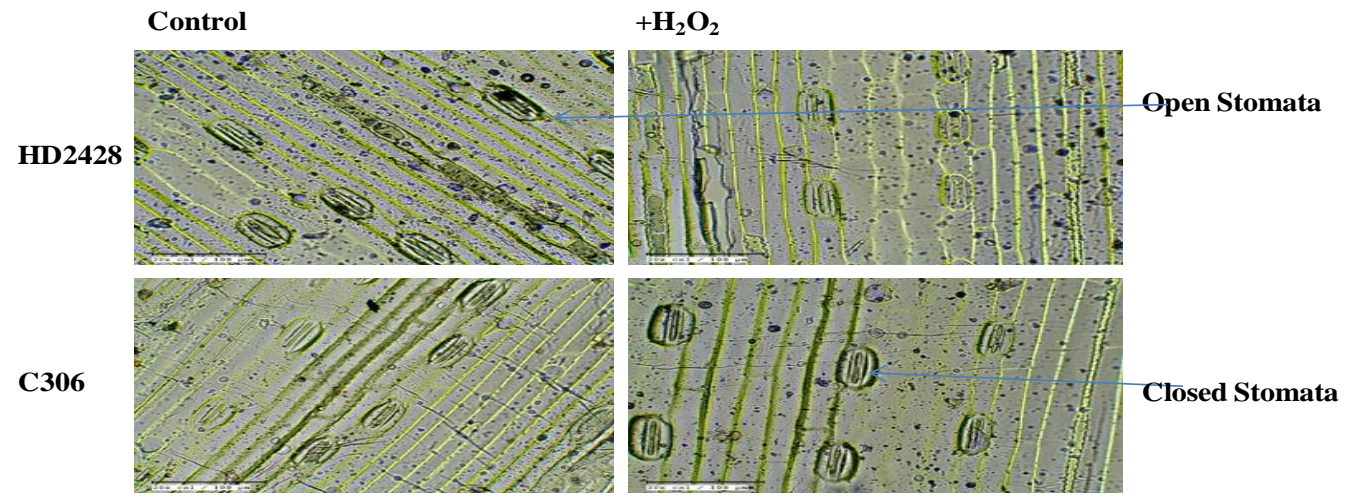

Fig2. Stomatal opening (20X) altered with hydrogen peroxide spray treatment in November sown wheats

Fig.2a

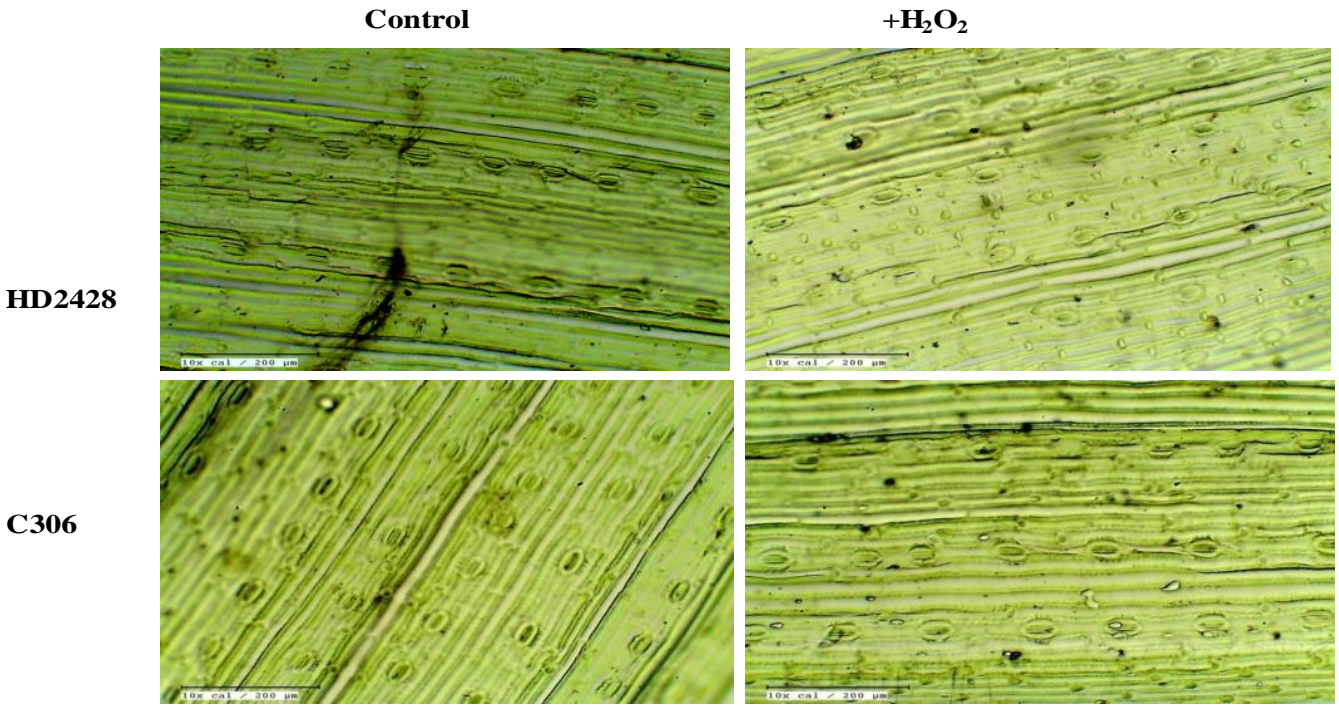

Fig2A. Stomatal opening (20X) altered with hydrogen peroxide spray treatment in January sown wheats 
Fig.2b

HD2428
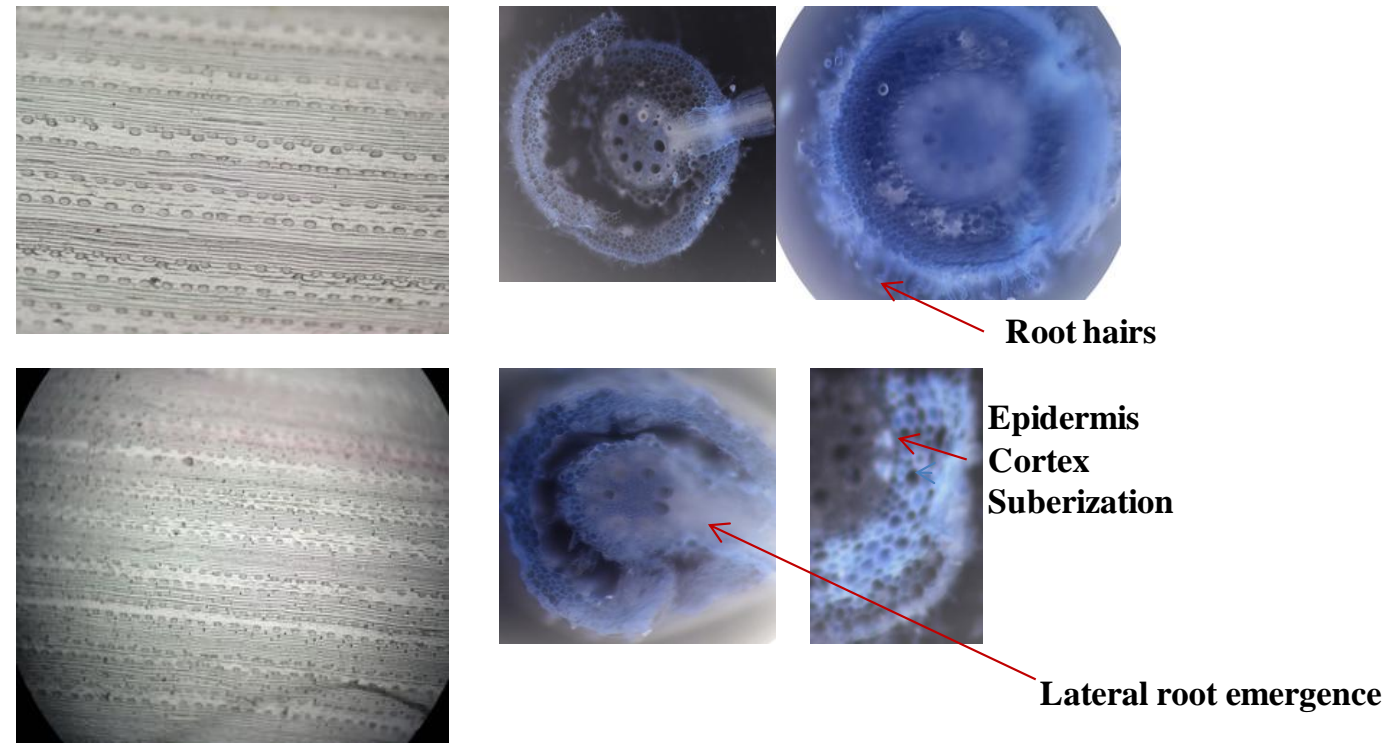

Fig2B. Reduced stomatal size, increased stomatal number on the larger flag leaf of hydrogen peroxide treated plant; suberin formation in the root cortex, significant reduction in root hairs and increased diameter of root under normal growth conditions in November sown wheat

Fig.3

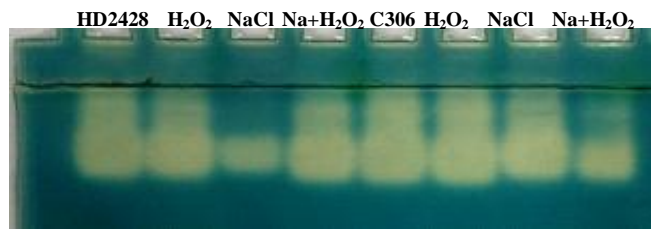

CAT1

CAt2

CAT3

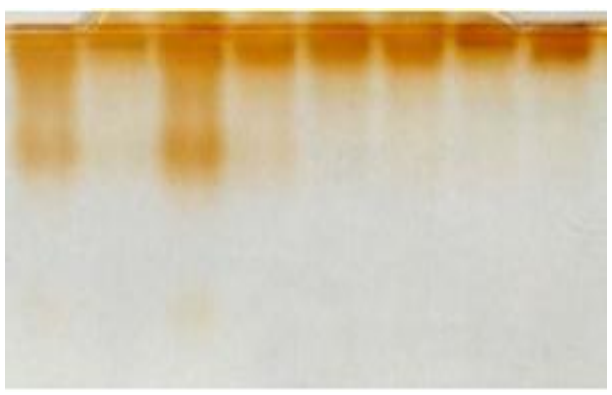

POX1

POX2

POX3

POX4

Fig3. Catalase (CAT) and Guaiacol Peroxidase (POX) isoenzymes in roots under 200mM NaCland in combination with hydrogen peroxide spray in January sown wheats 
Superoxide dismutase (SOD) is the first enzyme in the detoxifying process, which converts superoxide anion to $\mathrm{H}_{2} \mathrm{O}_{2}$ (Scandalios, 1993). The principal $\mathrm{H}_{2} \mathrm{O}_{2}$ scavenging enzyme in plants is catalase, which is located in peroxisomes/glyoxysomes and, at least in mitochondria (low in roots of November sown wheats). Catalase isozymes increased under drought in roots of January sown wheats and $\mathrm{H}_{2} \mathrm{O}_{2}$ spray treatment reduced the isozymes intensity (Fig. 3). SOD over expression accompanied with $\mathrm{H}_{2} \mathrm{O}_{2}$ scavenging system confers tolerance under water stress and cold stress. Catalase has high specificity for $\mathrm{H}_{2} \mathrm{O}_{2}$ and do not require reductants for scavenging activity and, is a mild oxidant against organic peroxides. Efficient $\mathrm{Cu}-\mathrm{ZnSOD}$ associated with generation of superoxide by $\mathrm{NAD}(\mathrm{P}) \mathrm{H}$ oxidase (Ogawa et al., 1996) and its product i.e. $\mathrm{H}_{2} \mathrm{O}_{2}$ is detoxified by peroxidase (present in apoplast and vacuoles) in suberin and lignin biosynthesis in C306 (Fig. 1B) and root hair growth in suberised epidermis of HD2428 under drought conditions. Peroxidase 3 and 4 in drought sensitive cultivar were involved in response to drought by $\mathrm{NaCl} /$ combined radiation and temperature (Fig. 3). $\mathrm{H}_{2} \mathrm{O}_{2}$ spray treatment decreased POX antioxidant enzyme under drought due to radiation and temperature in late sown HD2428 cultivar of wheat and trend was reversed in C306 (Fig. 3). Peroxidase isozymes number was higher in roots of drought sensitive cultivar of wheat. Remarkable increase in Catalase in roots was associated with removal of $\mathrm{H}_{2} \mathrm{O}_{2}$ via suberization. Reduced lignification in cortex of C306 was associated with increased root hairs (Fig. 1B) under $\mathrm{H}_{2} \mathrm{O}_{2}$ treatment.

Significant increase in stomatal density demonstrates the reduced stomatal and epidermal cell size in the stomatal patterning in both wheats (Fig. 2B). Therefore, involvement of abscisic acid in reduced cell size, stomatal development, stomatal conductance and alterations in root growth cannot be ruled out in hydrogen peroxide treated plants. The reduced distance between two stomata on alternate epidermal cells (ordered pattern) in $\mathrm{H}_{2} \mathrm{O}_{2}$ treated plants indicate mediation of plant growth inhibitor ABA in a concentration dependent manner (epigenetic wheats from our study).

Superoxide radical is not dismutated to $\mathrm{H}_{2} \mathrm{O}_{2}$ when CuZn-SOD is inhibited with spray treatment and interaction of superoxide with POX generate inactive compound (Metodiewa et al., 1992) instead of lignification in epidermis and guard cells resulting in partially open stomata.

\section{Acknowledgement}

Help provided in Light microscopy by Pharmacology Department of AIIMS, Delhi is thankfully acknowledged.

\section{References}

Beauchamp and Fridovich. 1971

Beauchamp C. and Fridovich I. (1971) Superoxide dismutase: improved assay and an assay applicable to acrylamide gels. Anal. Biochem. 44: 276-287.

Chen Z. and Gallie, D. R. (2004) The ascorbic acid redox state controls guard cell signalling and stomatal movement. Plant Cell 16: 1143-1162.

Danon A., Miersch O, Felix G., Camp R. C. and Apel K. (2005) Concurrent activation of cell death -regulating signalling pathways by singlet oxygen in Arabidopsis thaliana. Plant Journal, 41: 68-80.

Desikan R., Last K., Harrett-Williams R., Tagliavia K., Harter J. T., Hooley C., Hancock R. and Neill S.J. (2006) Ethylene-induced stomatal closure in Arabidopsis occurs via 
AtrbohF-mediated hydrogen peroxide synthesis. Plant Journal, 47: 907-916.

Jannat R., Uraji M., Morofuji M., Islam M. M., Bloom R. E., Nakamura Y., McClung C. R., Schroeder J. I., Mori I. C. and Murata Y. (2011) Roles of intracellular hydrogen peroxide accumulation in abscisic acid signalling in Arabidopsis guard cells. J Plant Physiol. 168(16):1919-26.

Metodiewa D., de Melo M. P. and Escobar, J. A. (1992) Horseradish peroxidasecatalyzed aerobic oxidation and peroxidation of indoIe-3-aceticacid. Arch. Biochem. Biophys. 296: 27-33.

Ogawa, K., Kanematsu S. and Asada K. (1996) Intra- and extra-cellular localization "cytosolic" CuZnsuperoxide dismutase in spinach leaf and hypocotyl. Plant Cell Physiol. 37: 790-799.

Quan L., Zhang B., Shi W. and Li H. (2008) Hydrogen peroxide in plants: a versatile molecule of the reactive oxygen species network. J. Integr. Plant Biol. 50: 2-18.

Salomon M., Christie J. M, Knieb E., Lempert U., Briggs W. R. (2000) Photochemical and mutational analysis of the FMNbinding domains of the plant blue light receptor, phototropin. Biochemistry, 39(31): 9401-9410.

Santosh Kumari (2010) Cellular changes and their relationship to morphology, abscisic acid accumulation and yield in wheat (Triticum aestivum) cultivars under water stress. American J. Plant Physiol., 5(5): 257-277.

Scandalios J. G. (1993) Oxygen stress and superoxide dismutases. Plant Physiol., 100: 7-12.

Tanaka Y., Sano T., Tamaoki M., Nakojima N., Kondo N. and Hasezawa S. (2005) Ethylene inhibits abscisic acid -induced stomatal closure in Arabidopsis. Plant Physiology 138: 2337-2343.

Ulmer R.L., Haskins F. A., and Akeson W. R. (1971) Influence of iron supply on peroxidase activity and peroxidase isozymes in corn (Zea mays). Crop Science 11: 816-818.

Woodbury W., Spencer A. K. and Stahmann M. A. (1971) An improved procedure using ferricyanide for detecting catalase isozymes. Anal Biochem. 44: 301-305.

\section{How to cite this article:}

Santosh Kumari and Vipin Kumar Verma. 2019. Hydrogen Peroxide Mediates Suberization, Root Thickness and Stomatal Movement in Wheats. Int.J.Curr.Microbiol.App.Sci. 8(04): 24482454. doi: https://doi.org/10.20546/ijcmas.2019.804.285 